\title{
The return of fixed combinations in psychiatry: fluoxetine and olanzapine combination
}

\author{
Richard C Shelton \\ Department of Psychiatry, \\ Department of Pharmacology, \\ Vanderbilt University School of \\ Medicine, Nashville, TN, USA
}

Correspondence: Richard C Shelton Department of Psychiatry, Department of Pharmacology, Vanderbilt University School of Medicine, I500 2 I st Avenue, South, Suite 2200, Nashville, TN 372I2, USA

Tel + I 6153439669

$\mathrm{Fax}+$ | 6153437868

Email richard.shelton@vanderbilt.edu

\begin{abstract}
Fixed combination psychotropics, such as a combination of a tricyclic and a typical antipsychotic, were widely prescribed a generation ago. These products were plagued by a number of problems, including serious side effects, which caused them to fall out of favor. More recently, a fixed combination of the atypical antipsychotic olanzapine and the serotonin selective reuptake inhibitor (SSRI) fluoxetine has been approved in the US for the treatment of bipolar I depression. Although the combination produced a robust clinical response relative to placebo or olanzapine alone, the response from practitioners has been mixed. The reasons for this are likely to be varied. Some practitioners who remember the earlier era of fixed combinations may simply be resistant to using products of this type. Moreover, the two constituents are available and many clinicians prescribe them independently. Finally, adverse events associated with olanzapine may make practitioners hesitant. For example, weight gain is a common side effect with olanzapine, and may be associated with hyperlipidemia or type II diabetes. Aggressive management of this problem appears to be helpful in preventing or reversing weight gain. It is not clear how weight gain is going to impact the uptake of this effective treatment.
\end{abstract}

Keywords: combination, atypical, antipsychotic, antidepressant, bipolar disorder, depression, weight

\section{Introduction}

Fixed combinations of drugs are common in medicine and, at one time, were common in psychiatry. A generation ago, a combination of antidepressants with either antipsychotics (eg, amitriptyline plus perphenazine $\left[\right.$ Etrafon $^{\mathrm{TM}}$, Triavil $^{\mathrm{TM}}$ ]) or benzodiazepines (eg, amitriptyline plus chlordiazepoxide [Limbitrol ${ }^{\mathrm{TM}}$ ]) were widely used by both psychiatrists and other medical practitioners. Several basic problems arose: although these combinations contained antidepressants, the dose in each capsule was small, eg, 10-25 mg. of amitriptyline. Thus, the vast majority of patients were substantially underdosed for depression. Unfortunately, many patients overdosed with these lethal combinations of drugs or committed suicide by other means. In effect, an insufficient dose of drug was given to treat depression, but a lethal quantity was prescribed.

In addition, many patients who were prescribed the antidepressant-antipsychotic combinations did not carry a psychotic diagnosis. Regrettably, exposure to the older, "typical" or "conventional" antipsychotics resulted in countless cases of tardive dyskinesia (TD), a permanent syndrome of abnormal involuntary movements involving the face, limbs, and trunk. This is a disfiguring and, at times, disabling consequence. Therefore, using these combinations added a completely unnecessary risk. These preparations were plagued by side effects and other untoward outcomes such as falls or motor vehicle accidents. These fixed combinations fell out of favor 
by the early 1980 s and were seldom used. In fact, a generation of psychiatrists has been trained with the specter of fixed combination therapies producing unnecessary risks without additional benefits above their component compounds, generating a situation in which practitioners have resisted using combination drugs.

Against this backdrop a fixed combination of the antipsychotic drug olanzapine and the antidepressant fluoxetine $\left(\operatorname{Symbiax}^{\mathrm{TM}}\right)$ has been introduced in the US for the treatment of bipolar depression. This review is intended to summarize the data supporting this introduction.

\section{Olanzapine and fluoxetine: pharmacology}

Fluoxetine is a relatively selective serotonin reuptake inhibitor, with an inhibition constant (Ki) for the serotonin transporter at $\sim 2.0 \mathrm{nmol} / \mathrm{L}$ as opposed to the affinity for the norepinephrine transporter at $>400 \mathrm{nmol} / \mathrm{L}$ (Owens et al 1997). There is a single active metabolite, norfluoxetine, which also is serotonin transporter selective. Fluoxetine and the metabolite each have very long half-lives, yielding an effective half-life of $>50$ hours (Lemberger et al 1985).

Olanzapine is a member of a group of antipsychotic drugs referred to as "novel" or "atypical". The term "atypical" refers to the therapeutic profile of these agents against the classical antipsychotics such as chlorpromazine and haloperidol. This large group of drugs differ significantly from the older medications based on a dissociation of their therapeutic effects from extrapyramidal (Parkinsonian) side effects. Older, "typical" antipsychotics achieved their therapeutic effect predominantly via dopamine-2 (D2) receptor blockade. Hence, therapeutic potency, derived from D2 receptor blockade in the mesolimbic dopamine pathways, was directly proportional to $\mathrm{D} 2$ receptor blockade in the striatum, which produced extrapyramidal symptoms. The atypicals, on the other hand, are weak D2 antagonists; this is particularly true of the prototypical drug of the class, clozapine (Meltzer 1991).

However, these drugs produce adequate and, perhaps, superior antipsychotic effects without potent D2 receptor blockade. Olanzapine is a modestly potent D2 antagonist $(\mathrm{Ki}=11 \mathrm{nmol} / \mathrm{L})$; however, like other drugs of the class, it is a significantly more robust blocker of serotonin (5-HT) $2 \mathrm{~A}(5-\mathrm{HT} 2 \mathrm{~A})$ receptors $(\mathrm{Ki}=2.5)$, which is though to be part of the basis for a superiority of typicals (Bymaster, Calligaro, et al 1996; Bymaster, Hemrick-Luecke, et al 1996). However, olanzapine also binds inhibits 5-HT2C, 5HT3, 5-HT8, as well as norepinephrine (NE) alpha1, muscarinic cholinergic, histamine1, and glutaminergic receptors. However, relatively weak D2 coupled with more potent 5-HT2A antagonism seems to contribute the enhanced therapeutic effects (Meltzer 1991; Meltzer et al 1989, 2003). The modest D2 binding can be thought of as competitively inhibiting the binding of dopamine, rather than following high saturation kinetics. This has been referred to as a "modulatory" role, antagonizing high levels of dopamine transmission without fully blocking the receptor. This property, along with the binding to 5-HT receptors, may yield improved effects on the cognitive, mood, and negative symptoms associated with schizophrenia (Tollefson and Sanger 1999; Meltzer et al 2003). These properties may be responsible for the unique interaction of olanzapine with the serotonin selective reuptake inhibitor (SSRI) fluoxetine.

In a study designed to test the interaction between fluoxetine and olanzapine, rats were administered the antipsychotic drugs olanzapine, clozapine, risperidone, or haloperidol, or the 5- $\mathrm{HT}_{2 \mathrm{~A}}$ antagonist MDL 100,907, with and without the SSRIs fluoxetine and sertraline. Olanzapine, risperidone, clozapine, and fluoxetine (but not haloperidol or MDL 100,907) given alone, modestly raised norepinephrine and dopamine levels (mean increases of 133\%-194\% baseline). Combining olanzapine or risperidone with fluoxetine substantially increased dopamine and norepinephrine levels; olanzapine: norepinephrine $=260 \%$, dopamine $=332 \%$; risperidone: norepinephrine $=200 \%$, dopamine $=255 \%$, although this was not seen with clozapine, haloperidol, or MDL 100,907. Increasing frontal and nucleus accumbens norepinephrine and dopamine has been an hypothesized mechanism for the enhanced antidepressant effects of the combination (Shelton 2003).

\section{Olanzapine plus fluoxetine in treatment-resistant unipolar major depression}

An early paper reported that the combination of risperidone (another atypical antipsychotic) given openly with SSRIs was beneficial for 8 patients with unipolar major depression who were unresponsive to an SSRI alone (Ostroff and Nelson 1999). This was followed by a relatively small double-blind, placebo-controlled trial of the combination of olanzapine and fluoxetine in non-psychotic, non-bipolar depressed patients who had not experienced adequate response to a trial of an SSRI (Shelton et al 2001). Initially, these patients were treated openly with up to $60 \mathrm{mg}$ /day of fluoxetine; those who experienced a $\geq 30 \%$ improvement in depression were excluded from a subsequent double-blind 
phase. Patients were randomized to receive olanzapine plus placebo $(n=8)$, continuation fluoxetine plus placebo $(n=10)$, or olanzapine plus fluoxetine $(n=10)$. The combined treatment resulted in a robust significant improvement by the end of the first week that was sustained through the entire 8-week double blind period. By contrast, continuation fluoxetine produced no additional effect and olanzapine alone resulted in an effect over the first three weeks with a relapse back to baseline depression; the latter effect has been attributed to the interaction between olanzapine and the falling plasma levels of fluoxetine and norfluoxetine, given their long half-lives (Shelton et al 2001).

Two subsequent large scale attempts to replicate this finding have resulted in failed trials. The initial run-in period was done with nortriptyline in one study (Shelton et al 2005) and venlafaxine in the other (Dube et al 2002), followed by a double-blind phase that included a continuation of the runin drug, fluoxetine alone, olanzapine alone, and the combined treatment. In both studies, combined olanzapine and fluoxetine produced the same robust response, but the other groups produced an equivalent effect by the end of the double-blind period. Because the groups treated with the run-in medication produced a full response by the end of this period indicates that they did not include truly treatment-resistant patients. As well, the mean doses of both fluoxetine and olanzapine were lower than in the previous trial. Given these failed trials, further studies will be needed to determine if this combination is indeed effective in treatment-resistant unipolar depression.

\section{Olanzapine and fluoxetine in bipolar depression}

Subsequent to the small-scale olanzapine-fluoxetine study noted earlier (Shelton et al 2001), a large $(n=833)$ doubleblind, placebo-controlled trial was conducted to compare olanzapine alone, combined olanzapine and fluoxetine, and placebo in bipolar I depression. Patients were assigned to receive olanzapine plus placebo, olanzapine plus fluoxetine, or placebo alone. The dose of olanzapine alone ranged between $5 \mathrm{mg}$ /day to $20 \mathrm{mg} /$ day (mean 9.7) and the olanzapine-fluoxetine was given in fixed combinations of $6 / 25,6 / 50,12 / 25$, and $12 / 50 \mathrm{mg} /$ day (mean 7.4/39.3) (Tohen, Vieta, et al 2003). The doses of the combination were derived from the mean olanzapine $(\sim 12 \mathrm{mg} /$ day $)$ and fluoxetine $(50 \mathrm{mg} /$ day $)$ doses in the earlier study in treatment-resistant patients. Both olanzapine alone and the combination were statistically superior to placebo on the main outcome variable, the Montgomery-Åsberg Depression Rating Scale; mixed effects random regression model (MMRM) analysis $\mathrm{p}<0.002$, all weeks. However, the combined condition produced a significantly better response than the monotherapy; MMRM p $<0.02$, weeks 4-8. Of significance is that olanzapine given singly yielded effects predominantly in vegetative symptoms (eg, sleep and appetite), whereas the combination was more effective on "core symptoms" of depression such as depressed mood and negative thinking. Both olanzapine and the combination showed significant differences in change from baseline to endpoint on the Hamilton Anxiety Scale (Hamilton 1959), the Clinical Global Impressions Scale for Bipolar Disorder, and the Young Mania Rating Scale (Young et al 1978), although the scores on the latter were very low in all groups. This single trial served as the basis of the approval by the US Food and Drug Administration of combined olanzapine and fluoxetine for bipolar depression (Symbiax).

Olanzapine has been shown to be effective for acute mania (Tohen et al 2002) as well as producing long-term mood stabilizing effects (Tohen et al 2002, 2005; Tohen, Ketter, et al 2003; Baker et al 2004). One concern about the combination is that the addition of an antidepressant could counteract the long term prevention of mania or depression, given the apparent propensity of antidepressants to induce cycling in bipolar patients. However, longer-term data suggest that the combination is no more likely to induce mania or depression as are olanzapine alone or placebo (Keck et al 2005).

\section{A renaissance of combination psychotropics?}

Combined olanzapine-fluoxetine represents the first fixeddose combination psychotropic treatment approved in the US for many years. Early uptake has been limited at best, and a number of factors seem to be limiting its use. As noted earlier, there may be an inherent resistance among psychiatrists to using combination psychotropics because of the history of negative experiences with combined treatments. However, concerns about adverse effects with olanzapine, whether given alone or in combination with fluoxetine, seem to predominate.

The side effect profile of the combination is consistent with that of olanzapine and fluoxetine, and includes asthenia, somnolence, tremor, diarrhea, dry mouth, increased appetite, and weight gain. In spite of a relatively low affinity for D2 receptors and limited problems with extrapyramidal side effects, olanzapine has been shown to significantly elevate 
prolactin, which may cause sexual dysfunction, osteoporosis, amenorrhea, gynecomastia, or galactorrhea (Saito et al 2004; Melkersson 2005). Tardive dyskinesia is a syndrome of abnormal involuntary movements induced by long-term use of D2 receptor blocking agents (eg, chlorpromazine). These movements involve the mouth, face, neck, trunk, or extremities, and can be disfiguring or debilitating. The rates of TD with all the atypical antipsychotics are low, but finite at less than 1\%. However, any risk can be problematic given the availability of mood stabilizing drugs other than the antipsychotics.

The most salient concerns among practitioners, however, have been weight gain, elevated lipids, and type II diabetes with olanzapine (Newcomer 2005). The use of olanzapine has dropped sharply in the recent past, and the acceptance of the olanzapine-fluoxetine (Symbiax) combination has been modest. A number of strategies have been investigated for the control of weight gain. These include standard weight management methods (eg, diet and exercise counseling) (Ball et al 2001; Evans et al 2005). Furthermore, several drugs have been tried to reduce the weight gain problems. These include the putative appetite suppressing anticonvulsants topiramate (Levy et al 2003) or sibutramine (Henderson et al 2005), the histamine-2 antagonists (eg, nizatidine) (Cavazzoni et al 2003), or the selective norepinephrine uptake inhibitor reboxetine (Poyurovsky et al 2003). Although reboxetine is not available in the US, similarly acting drugs are available (eg, atomoxetine). Assertive weight management from the start of treatment is recommended. Moreover, weight should be monitored and waist circumference measurements can be used (Straker et al 2005). As well, blood lipids should be measured routinely. A suggested schedule would be 3, 6, and 12 months, and biannually thereafter (Baptista et al 2002; Chue and Kovacs et al 2003).

The potential for long-term antidepressant use to exacerbate bipolar disorder may affect the use of this fixed combination, in spite of the fact that both short- (Tohen, Vieta, et al 2003) and longer-term data do not support this concern. As well, the availability of other treatments, including alternative atypical antipsychotics, without weight gain problems has exacerbated this issue (Seemuller et al 2005). Although the data in bipolar disorder with other atypical drugs are more limited, practitioners have tended to select more weight neutral compounds. Treatments such as lamotrigine (Bowden et al 1999; Calabrese et al 1999) and lithium (Nemeroff et al 2001) also are often used, even though the data also are limited. It remains unclear whether the effect is limited to fluoxetine, or if other if other serotonin uptake inhibitors may be equally effective. In particular, practitioners have the option of adding olanzapine to another antidepressant and not switch to Symbiax. Finally, practitioners may not prefer to be limited to the available dosage combinations, even though they provide considerable flexibility.

Is this a renaissance of fixed combination psychotropics? Given its robust effect, Symbiax is an important alternative for bipolar depression, an extremely difficult-to-treat condition. Alternatively, uptake of the product has been limited, which is likely to be the result of a variety of issues. It remains to be seen whether this or any other fixed combination will become an important part of clinical practice in the future.

\section{References}

Baker RW, Brown E, Akiskal HS, et al. 2004. Efficacy of olanzapine combined with valproate or lithium in the treatment of dysphoric mania. Br J Psychiatry, 185:472-8

Ball MP, Coons VB, Buchanan RW. 2001. A program for treating olanzapine-related weight gain. Psychiatr Serv, 52:967-9.

Baptista T, Kin NM, Beaulieu S, et al. 2002. Obesity and related metabolic abnormalities during antipsychotic drug administration: mechanisms, management and research perspectives. Pharmacopsychiatry, 35: 205-19.

Bowden CL, Mitchell P, Suppes T. 1999. Lamotrigine in the treatment of bipolar depression. Eur Neuropsychopharmacol, 9(Suppl 4):S113-17.

Bymaster FP, Calligaro DO, Falcone JF, et al. 1996. Radioreceptor binding profile of the atypical antipsychotic olanzapine. Neuropsychopharmacology, 14:87-96.

Bymaster FP, Hemrick-Luecke SK, Perry KW et al. 1996. Neurochemical evidence for antagonism by olanzapine of dopamine, serotonin, alpha(1)-adrenergic and muscarinic receptors in vivo in rats. Psychopharmacology, 124:87-94.

Calabrese JR, Bowden CL, Sachs GS, et al. 1999. A double-blind placebocontrolled study of lamotrigine monotherapy in outpatients with bipolar I depression. Lamictal 602 Study Group. J Clin Psychiatry, 60: $79-88$.

Cavazzoni P, Tanaka Y, Roychowdhury SM, et al. 2003. Nizatidine for prevention of weight gain with olanzapine: a double-blind placebocontrolled trial. Eur Neuropsychopharmacol, 13:81-5.

Chue P, Kovacs CS. 2003. Safety and tolerability of atypical antipsychotics in patients with bipolar disorder: prevalence, monitoring and management. Bipolar Disord, 5(Suppl 2):62-79.

Dube S, Paul S, Sanger T, et al. 2002. Olanzapine-fluoxetine combination in treatment-resistant depression. Eur Psychiatry, 17(Suppl 1):98.

Evans S, Newton R, Higgins S. 2005. Nutritional intervention to prevent weight gain in patients commenced on olanzapine: a randomized controlled trial. Aust NZ J Psychiatry, 39:479-86.

Hamilton M. 1959. The assessment of anxiety states by rating. Br J Med Psychol, 32:50-5.

Henderson DC, Copeland PM, Daley TB, et al. 2005. A double-blind, placebo-controlled trial of sibutramine for olanzapine-associated weight gain. Am J Psychiatry, 162:954-62.

Keck PE Jr, Corya SA, Altshuler LL, et al. 2005. Analyses of treatmentemergent mania with olanzapine/fluoxetine combination in the treatment of bipolar depression. J Clin Psychiatry, 66:611-16. 
Lemberger L, Bergstrom RF, Wolen RL, et al. 1985. Fluoxetine: clinical pharmacology and physiologic disposition. J Clin Psychiatry, 46: 14-19.

Levy E, Margolese HC, Chouinard G. 2003. Topiramate produced weight loss following olanzapine-induced weight gain in schizophrenia. JClin Psychiatry, 63:1045.

Melkersson K. 2005. Differences in prolactin elevation and related symptoms of atypical antipsychotics in schizophrenic patients. J Clin Psychiatry, 66:761-7.

Meltzer HY. 1991. The mechanism of action of novel antipsychotic drugs. Schizophr Bull, 17:263-87.

Meltzer HY, Bastani B, Ramirez L, et al. 1989. Clozapine: new research on efficacy and mechanism of action. Eur Arch Psychiatry Neurol Sci, 238:332-9.

Meltzer, HY, Li Z, Kaneda Y, et al. 2003. Serotonin receptors : their key role in drugs to treat schizophrenia. Biol Psychiatry, 27:1159-72.

Nemeroff CB, Evans DL, Gyulai L, et al. 2001. Double-blind, placebocontrolled comparison of imipramine and paroxetine in the treatment of bipolar depression. Am J Psychiatry, 158:906-12.

Newcomer JW. 2005. Second-generation (atypical) antipsychotics and metabolic effects: a comprehensive literature review. CNS Drugs, 19(Suppl 1):1-93.

Ostroff RB, Nelson JC. 1999. Risperidone augmentation of selective serotonin reuptake inhibitors in major depression. J Clin Psychiatry, 60:256-9.

Owens MJ, Morgan WN, Plott SJ, et al. 1997. Neurotransmitter receptor and transporter binding profile of antidepressants and their metabolites. J Pharmacol Exp Ther, 283:1305-22.

Poyurovsky M, Isaacs I, Fuchs C, et al. 2003. Attenuation of olanzapineinduced weight gain with reboxetine in patients with schizophrenia: a double-blind, placebo-controlled study. Am J Psychiatry, 160: 297-302.

Saito E, Correll CU, Gallelli K, et al. 2004. A prospective study of hyperprolactinemia in children and adolescents treated with atypical antipsychotic agents. $J$ Child Adolesc Psychopharmacol, 14: 350-8.
Seemuller F, Forsthoff A, Dittmann S, et al. 2005. The safety and tolerability of atypical antipsychotics in bipolar disorder. Expert Opin Drug Saf, 4:849-68.

Shelton RC. 2003. The combination of olanzapine and fluoxetine in mood disorders. Expert Opin Pharmacother, 4:1175-83.

Shelton RC, Tollefson GD, Tohen M, et al. 2001. A novel augmentation strategy for treating resistant major depression. Am J Psychiatry, 158:131-4.

Shelton RC, Williamson D, Corya SA, et al. 2005. Olanzapine/fluoxetine combination for treatmentresistant depression: A controlled study of SSRI and nortriptyline resistance. J Clin Psychiatry, 66:1289-97.

Straker D, Correll CU, Kramer-Ginsberg E, et al. 2005. Cost-effective screening for the metabolic syndrome in patients treated with secondgeneration antipsychotic medications. Am J Psychiatry, 162: 1217-21.

Tohen M, Baker RW, Altshuler LL, et al. 2002. Olanzapine versus divalproex in the treatment of acute mania. Am J Psychiatry, 159: 1011-17.

Tohen M, Greil W, Calabrese JR, et al. 2005. Olanzapine versus lithium in the maintenance treatment of bipolar disorder: a 12-month, randomized, double-blind, controlled clinical trial. Am J Psychiatry, 162:1281-90.

Tohen M, Ketter TA, Zarate CA, et al. 2003. Olanzapine versus divalproex sodium for the treatment of acute mania and maintenance of remission: a 47-week study. Am J Psychiatry, 160:1263-71.

Tohen M, Vieta E, Calabrese J, et al. 2003. Efficacy of olanzapine and olanzapine-fluoxetine combination in the treatment of bipolar I depression. Arch Gen Psychiatry, 60:1079-88.

Tollefson GD, Sanger TM. 1999. Anxious-depressive symptoms in schizophrenia: a new treatment target for pharmacotherapy? Schizophr Res, 35(Suppl):S13-S21.

Young RC, Biggs JT, Ziegler VE, et al. 1978. A rating scale for mania: reliability, validity and sensitivity. Br J Psychiatry, 133:429-35. 
